\title{
Tratamentos pré-germinativos para superação da dormência de sementes de Sterculia striata A. St. Hil. Naldin
}

\section{Pre-germinative treatments to overcome dormancy of Sterculia striata A. St. Hil. \& Naldin seeds}

\author{
Kelina Bernardo Silva ${ }^{1 *}$; Marlene Feliciano Mata ${ }^{2}$; \\ Riselane de Lucena Acântara Bruno ${ }^{3}$
}

\section{Resumo}

\begin{abstract}
Sterculia striata A. St. Hil. \& Naudin. é uma espécie nativa que é utilizada em reflorestamentos e na arborização urbana. Apresenta sementes duras, consistindo em problema para os viveiristas, uma vez que seus tegumentos duros e impermeáveis à água dificultam e retardam a germinação. $\mathrm{O}$ presente estudo teve como finalidade determinar o efeito de tratamentos pré-germinativos no processo de germinação de sementes de Sterculia striata. As sementes foram submetidas a seis tratamentos: testemunha - sementes intactas $\left(\mathrm{T}_{1}\right)$, escarificação com lixa n. 80 no lado oposto à micrópila $\left(\mathrm{T}_{2}\right)$, escarificação com ácido sulfúrico concentrado por 15,45 e 60 minutos $\left(\mathrm{T}_{3}, \mathrm{~T}_{4}, \mathrm{e} \mathrm{T}_{5}\right.$, respectivamente) e escarificação com lixa seguida de imersão em água por 24 horas $\left(\mathrm{T}_{6}\right)$. As características avaliadas foram: emergência de plântulas, primeira contagem de emergência, índice de velocidade de emergência, bem como comprimento e massa seca da parte aérea e raiz das plântulas. $O$ tratamento de escarificação com lixa $\mathrm{n}^{\mathrm{o}} 80$ no lado oposto a micrópila favorece a porcentagem de plântulas na primeira contagem, sendo recomendado para acelerar e uniformizar a emergência de sementes de Sterculia striata.
\end{abstract}

Palavras-chave: Chichá, espécies florestais, germinação

\begin{abstract}
Sterculia striata A. St. Hil. \& Naudin. is a native species that is used in reforestation and urban forestry. Displays hard seeds, consisting of problem for the nursery, since their hard seed coats and waterproof hinder and delay germination. This study aimed to determine the effect of pre-germinative treatments in the process of germination of Sterculia striata. The seeds were subjected to six treatments: control intact seeds $\left(\mathrm{T}_{1}\right)$, mechanical scarification with sandpaper. 80 opposite the micropylar $\left(\mathrm{T}_{2}\right)$ with sulfuric acid concentrated by 15,45 and 60 minutes $\left(\mathrm{T}_{3}, \mathrm{~T}_{4}\right.$ and $\mathrm{T}_{5}$ respectively) scarification and then immersion in water for 24 hours $\left(\mathrm{T}_{6}\right)$. The characteristics evaluated were: seedling emergence, emergency first count, speed of emergence, as well as length and dry mass of shoot and root of seedlings. The scarification with sandpaper number 80 on the opposite side of micropylar favors the percentage of seedlings in the first count, and recommended rapid and uniform emergence of seeds of Sterculia striata.
\end{abstract}

Key words: Chichá, forest species, germination

${ }_{1}$ Prof $^{a}$ Adjunta, Dept ${ }^{\circ}$. de Agrárias e Exatas, Universidade Estadual da Paraíba, UEPB, Catolé do Rocha, PB. E-mail: kelinabernardo@yahoo.com.br

2 Doutoranda do curso de Pós-graduação em Agronomia, Universidade Federal da Paraíba, CCA, Areia, PB. E-mail: mfm@yahoo. com.br

${ }^{3}$ Prof $^{\mathrm{a}}$ Adjunta, Dept ${ }^{\circ}$. de Fitotecnia, Universidade Federal da Paraíba, CCA, Areia, PB. E-mail: lane@cca.ufpb.br

* Autor para correspondência 


\section{Introdução}

O chichazeiro (Sterculia striata A. St. Hil. \& Naudin), da família Malvaceae também é conhecido popularmente como chichazeiro-do-cerrado, mendubi-guaçu, aracha-chá, chechá-do-norte e castanha-de-macaco; nativa da região de MeioNorte de Brasil, cujo fruto, uma cápsula lenhosa e alongada, apresenta potencial para o mercado de nozes. A planta é decídua e mede entre 8 e $14 \mathrm{~m}$ de altura, com diâmetro de caule variando entre 0,4 e 0,5 m. Uma planta adulta, em suas condições naturais, pode produzir de 100 a 180 cápsulas com três ou quatro lóbulos cada por safra/ano (ARAÚJO, 1997).

O chichazeiro é uma planta pioneira, de rápido crescimento e tolerante a terrenos secos e pedregosos, sendo indicada para plantios destinados à recomposição de áreas degradadas de preservação permanente. A espécie tem potencial madeireiro, paisagístico e alimentar, pois seus frutos e sementes (nozes) podem ser consumidos in natura. A sua área de ocorrência abrange a região amazônica até o Piauí, Goiás, Mato Grosso, Minas Gerais, Mato Grosso do Sul e São Paulo, na floresta semidecídua e sua transição para o Cerrado (LORENZI, 2002).

A utilização do teste de germinação é fundamental para o monitoramento da viabilidade das sementes em bancos de germoplasma, antes e durante o armazenamento. Todavia, o conhecimento atual sobre as técnicas de monitoramento é limitado, concentrando-se, principalmente, em plantas de interesse agrícola.

A impermeabilidade do tegumento à água é o fenômeno considerado por Popinigis (1985) como uma das causas mais comuns de dormência nas sementes de plantas de diversas famílias. A importância ecológica da dormência baseia-se, principalmente, no bloqueio da germinação quando as condições ambientais são adequadas, porém as perspectivas de futuro estabelecimento e crescimento das plântulas não são promissoras (EIRA; CALDAS, 2000). Dessa forma, metodologias para a superação de dormência são importantes, particularmente, para o monitoramento da viabilidade de sementes (ELLIS; HONG; ROBERTS, 1985).

As sementes da maioria das espécies germinam prontamente quando lhes são dadas condições ambientais favoráveis (POPINIGIS, 1985; CARVALHO; NAKAGAWA, 2000). No entanto, segundo Kramer e Kozlowisk (1972), as sementes de cerca de dois terços das espécies arbóreas apresentaram certo grau de dormência, que pode ser superada com a utilização de tratamentos prégerminativos. Dessa forma, a dormência passa a ser um transtorno quando as sementes são utilizadas para produção de mudas, em virtude do longo tempo para que ocorra a germinação, ficando as mesmas sujeitas às condições adversas, o que favorece $\mathrm{o}$ ataque de fungos e, consequentemente, pode acarretar grandes perdas (BORGES et al., 1982).

As causas da dormência podem ser devidas à presença de embriões imaturos, tegumentos impermeáveis à água ou ao oxigênio, por restrições mecânicas ou pela presença de substâncias inibidoras da germinação (POPINIGIS, 1985; BEWLEY; BLACK, 1994). Espécies florestais tropicais, com sementes duras, freqüentemente apresentam consideráveis problemas para os viveiristas porque seus tegumentos duros e impermeáveis restringem a entrada de água e oxigênio, oferecendo assim, alta resistência física ao crescimento do embrião (MOUSSA et al., 1998).

Entre os métodos utilizados para superação da dormência tegumentar, a escarificação mecânica é uma técnica frequentemente utilizada e constitui a opção mais prática e segura para pequenos agricultores (HERMANSEN et al., 2000), além de ser um método simples, de baixo custo e eficaz para promover uma germinação rápida e uniforme. No entanto, deve ser efetuada com muito cuidado para evitar que a escarificação excessiva possa causar danos ao tegumento e diminuir a germinação (McDONALD; COPELAND, 1997).

A eficiência da escarificação mecânica foi 
constatada por Ormosia nitida Vog., Deminicis et al. (2006) para Leucaena leucocephala (Lam.) De Wit. e por Cruz e Carvalho (2006) para Schizolobium amazonicum Huber ex Ducke, cujas sementes apresentam características de dureza. Entretanto, esse tratamento não se mostrou eficiente na superação da dormência de sementes de Senna macranthera (Collad.) Irwin et Barn. (ESCHIAPATI-FERREIRA; PEREZ, 1997) e de Lathyrus nervosus Lam. (FRANKE; BASEGGIO, 1998). Segundo esses autores, tais resultados podem ser explicados pela ocorrência de injúrias nas sementes provocadas pela fricção mecânica ou pela diferença de constituição do tegumento de diferentes espécies de sementes. Dessa forma, a utilização de materiais abrasivos exige cuidados quanto à intensidade e à forma de aplicação, para não comprometer a qualidade das sementes.

A escarificação com ácido sulfúrico é eficiente na superação da dormência causada pela impermeabilidade do tegumetno, porém este é um produto de difícil manuseio e não encontrado facilmente no mercado. Sua eficácia foi comprovada na superação da impermeabilidade do tegumento de sementes de Zizyphus joazeiro Mart. (ALVES et al., 2006) e Senna siamea (Lam.) H.S. Irwin e Barneby (DUTRA et al., 2007).

O presente estudo teve como finalidade determinar o efeito de tratamentos pré-germinativos no processo de germinação de sementes de Sterculia striata.

\section{Material e Métodos}

\section{Coleta dos frutos e beneficiamento das sementes}

Os frutos foram coletados em janeiro de 2009, na área verde da colônia de férias Iparana, no município de Caucaia, CE, que está situado a $22^{\circ} 02^{\prime} \mathrm{S}$ e $45^{\circ}$ $50^{\prime} \mathrm{W}$ a $575 \mathrm{~m}$ de altitude. Foram selecionadas cinco árvores matrizes levando-se em consideração a intensidade de frutificação e o estado fitossanitário. A coleta foi realizada com auxílio de podão e as sementes extraídas manualmente dos frutos secos (coloração marrom) e transportadas em sacos de papel para o Laboratório de Análise de Sementes do Centro de Ciências agrárias da Universidade Federal da Paraíba, no município de Areia-PB. Após o beneficiamento as sementes foram submetidas aos seguintes testes:

Massa de mil sementes, número de sementes por fruto

Para determinação do peso de mil sementes, foram utilizadas oito sub-amostras de 100 (BRASIL, 2009). Quanto ao número de sementes por fruto, em uma amostra de 100 realizou-se contagem manual do número de sementes em cada fruto.

\section{Tratamentos para superação da dormência}

As sementes foram submetidas aos seguintes tratamentos: testemunha - sementes intactas $\left(\mathrm{T}_{1}\right)$, escarificação mecânica com lixa d'água $n^{\circ} 80$ na região oposta à micrópila $\left(\mathrm{T}_{2}\right)$, imersão das sementes em ácido sulfúrico concentrado por 15,45 e 60 minutos $\left(\mathrm{T}_{3}, \mathrm{~T}_{4}\right.$ e $\mathrm{T}_{5}$, respectivamente) e escarificação com lixa ${ }^{\circ} 80$, seguida de imersão em água fria por 24 horas $\left(\mathrm{T}_{6}\right)$. Na escarificação mecânica as sementes foram friccionadas manualmente em lixa d'água $n^{\circ}$ 80 até desgaste visível do tegumento no lado oposto à micrópila. Nos tratamentos com ácido sulfúrico as sementes permaneceram imersas pelos períodos mencionados anteriormente e, posteriormente foram lavadas em água corrente por uns dez minutos para a eliminação do produto.

As sementes após submetidas aos tratamentos, foram semeadas na profundidade de $2 \mathrm{~cm}$ em bandejas plásticas perfuradas no fundo, com dimensões de 29 × $22 \times 10 \mathrm{~cm}$ de comprimento, largura e profundidade, respectivamente, contendo areia lavada, previamente peneirada e esterilizada em autoclave. O substrato foi umedecido até se verificar início da drenagem natural, cuja manutenção da umidade foi por meio de irrigações 
diárias. As bandejas semeadas ficaram em estufa sem sombreamento, com temperatura média de 30 ${ }^{\circ} \mathrm{C}$.

Avaliaram-se as seguintes características: emergência de plântulas - foram utilizadas 100 sementes por tratamento, divididas em quatro subamostras de 25. As contagens do número de plântulas emergidas iniciaram-se aos dez dias após semeadura e estenderam-se até os 30 dias, utilizando-se como critério às plântulas normais que apresentavam os cotilédones acima do solo e os resultados foram expressos em porcentagem; primeira contagem de emergência - correspondente à porcentagem acumulada de plântulas normais no décimo dia após o início do teste; índice de velocidade de emergência (IVE) - foram realizadas contagens diárias das plântulas normais, durante 30 dias, e o índice calculado conforme a fórmula proposta por Maguire (1962); comprimento de plântulas - no final do teste de emergência, as plântulas normais de cada repetição foram medidas da ponta da raiz primária ate a gema apical, com o auxílio de uma régua graduada em centímetros, sendo os resultados expressos em centímetros por plântula; massa seca das plântulas - após a contagem final no teste de emergência, as plântulas foram secas em estufa regulada a $65^{\circ} \mathrm{C}$ até atingir massa constante e, decorrido esse período, pesadas em balança analítica com precisão de $0,001 \mathrm{~g}$, conforme Nakagawa (1999), sendo os resultados expressos em gramas por plântula.

$\mathrm{O}$ delineamento experimental utilizado foi $\mathrm{o}$ inteiramente ao acaso, constando de seis tratamentos, com quatro repetições. Os dados em porcentagem, sem transformações foram submetidos à análise de variância e a comparação entre as médias foi feita pelo teste de Tukey, a 5\% de probabilidade.

\section{Resultados e Discussão}

As sementes se encontravam com umidade em torno de $6,58 \%$. A média relativa da quantidade de sementes por fruto expressa uniformidade dos dados, demonstrado pelo baixo coeficiente de variação obtido, o qual foi de $3,4 \%$, enquanto para os dados de massa de mil sementes $(1.445,6 \mathrm{~g})$ houve uma baixa variação em relação à essa característica $(1,19$ \%) (Tabela 1).

Tabela 1. Massa de mil sementes, média do número de sementes por fruto e número de sementes por quilograma de S. striata.

\begin{tabular}{lll}
\hline Determinações & Média & CV (\%) \\
\hline $\mathrm{N}^{\circ}$ de sementes por fruto & 4,7 & 2,35 \\
Peso de mil sementes(g) & $1.445,6$ & 1,19 \\
\hline
\end{tabular}

Fonte: Elaboração dos autores.

As sementes submetidas à escarificação manual com lixa no lado oposto a micrópila $\left(\mathrm{T}_{2}\right)$ e imersão em ácido sulfúrico por 15 e 45 minutos $\left(\mathrm{T}_{4}\right.$ e $\mathrm{T}_{3}$, respectivamente) apresentaram as maiores porcentagens de emergência de plântulas, porém não diferindo estatisticamente da testemunha $\left(\mathrm{T}_{1}\right)$. As menores porcentagens de emergência foram obtidas com as sementes submetidas ao ácido sulfúrico por 60 minutos $\left(T_{5}\right)$ e aquelas escarificadas com posterior imersão em água fria por 24 horas, provavelmente devido ao fato de os mesmos terem provocado danos ao embrião das mesmas. Resultados semelhantes foram obtidos por Santos, Morais e Matos (2004) quando observaram que as maiores porcentagens de germinação de sementes de Sterculia foetida L. ocorreram com a utilização de escarificação mecânica em um lado da semente seguido de embebição e, escarificação mecânica nos dois lados, sem embebição.

De modo geral, a escarificação mecânica não aumentou a germinação da espécie estudada, no entanto, em outras espécies a escarificação manual com lixa favorece a germinação em sementes que apresentam tegumento impermeável à água, assim como sementes de Senna macranthera (SANTARÉM; AQUILA, 1995), Ocotea corymbosa (Meissn.) Mez (BILIA; BARBEDO; MALUF, 1998), Leucaena diversifolia (BERTALOT; 
NAKAGAWA, 1998), Operculina macrocarpa (MEDEIROS FILHO; FRANÇA; INNECCO, 2002), Acacia mearnsii (ROVERSI et al., 2002), Ormosia arborea (LOPES; DIAS; MACEDO, 2004), Schizolobium amazonicum (CRUZ; CARVALHO, 2006), Leucaena leucocephala (DEMINICIS et al., 2006) e Senna siamea (DUTRA et al., 2007).

Os tratamentos com ácido sulfúrico não se mostraram eficientes na quebra de dormência de sementes de Sterculia striata, não diferindo estatisticamente da testemunha. Contudo, em outros trabalho realizados os tratamentos com ácido sulfúrico proporcionaram aumentos e uniformização na germinação de sementes de Senna macranthera (ESCHIAPATI-FERREIRA; PEREZ, 1997), Parkia multijuga (BIANCHETTI; TEIXEIRA; MARTINS, 1998), Cassia excelsa (JELLER; PEREZ, 1999), Bauhinia monandra (ALVES et al., 2000), Mimosa caesalpiniifolia (GARCIA; DUARTE; FRASSETO, 2002), Ormosia arborea (LOPES; DIAS; MACEDO, 2004), Ochroma lagopus, (BARBOSA et al., 2004), Zizyphus joazeiro (ALVES et al., 2006) e Ormosia nitida (LOPES; DIAS; MACEDO, 2006).

$\mathrm{Na}$ primeira contagem de emergência destacaram-se as sementes escarificadas com lixa $\left(\mathrm{T}_{2}\right)$, com um porcentual de emergência de $61 \%$. Esses resultados demonstram que esse tratamento favoreceu a velocidade de emergência e a uniformidade de emergência das plântulas, quando avaliado pela porcentagem de plântulas na primeira contagem. Segundo Hartmann et al. (1997), para espécies que apresentam sementes com tegumento impermeável à água, a escarificação mecânica é um dos tratamentos mais comumente usados. Resultados semelhantes foram obtidos por Santos, Morais e Matos (2004) com Sterculia foetida, onde as sementes escarificadas nos dois lados, sem embebição apresentaram melhor desempenho germinativo na primeira contagem, seguidas por aquelas submetidas à escarificação mecânica em um lado seguida de embebição.

Com relação ao índice de velocidade de emergência (IVE), os tratamentos de escarificação com lixa no lado oposto a micrópila $\left(\mathrm{T}_{2}\right)$ e imersão em ácido sulfúrico $\left(\mathrm{T}_{3}\right)$ proporcionaram os melhores resultados, no entanto, não diferiram da testemunha $\left(\mathrm{T}_{1}\right)$ (Figura 1). A escarificação mecânica, por provocar fissuras no tegumento das sementes, aumenta a sua permeabilidade, permitindo a embebição e a aceleração do início do processo de germinação (FRANKE; BASEGGIO, 1998).

Os maiores índices de velocidade de germinação de sementes de Acacia mearnsii (ROVERSI et al., 2002), Sterculia foetida (SANTOS; MORAIS; MATOS, 2004), Bowdichia virgilioides (SMIDERLE; SOUSA, 2003) e Schizolobium amazonicum (CRUZ; CARVALHO, 2006), e o maior vigor (índice de velocidade de germinação) ocorreu quando se empregou a escarificação mecânica. Contudo, com a espécie em estudo não se comprovou essa eficácia, visto que o IVG não apresentou diferença estatística entre os tratamentos.

Os dados de comprimento da raiz principal, assim como, massa seca de raízes e parte aérea não apresentaram diferença entre os tratamentos estudados (Figura 2). Quanto ao comprimento de parte aérea, os maiores valores foram obtidos com o tratamento de escarificação mecânica com lixa $\left(T_{2}\right)$, seguido pelos tratamentos de imersão em ácido sulfúrico por 45 e 60 minutos $\left(\mathrm{T}_{4}\right.$ e $\mathrm{T}_{5}$, respectivamente). Esses resultados devem-se, provavelmente, a um menor consumo das reservas das sementes durante o processo germinativo, uma vez que a mesma ocorreu de forma rápida e uniforme. Resultados diferentes foram obtidos por Sampaio et al. (2001) quando observaram redução no crescimento de plântulas de Bowdichia virgilioides com a imersão das sementes em ácido sulfúrico concentrado por períodos superiores a dois minutos. 
Figura 1. Emergência, primeira contagem e índice de velocidade de emergência de plântulas de S. striata.
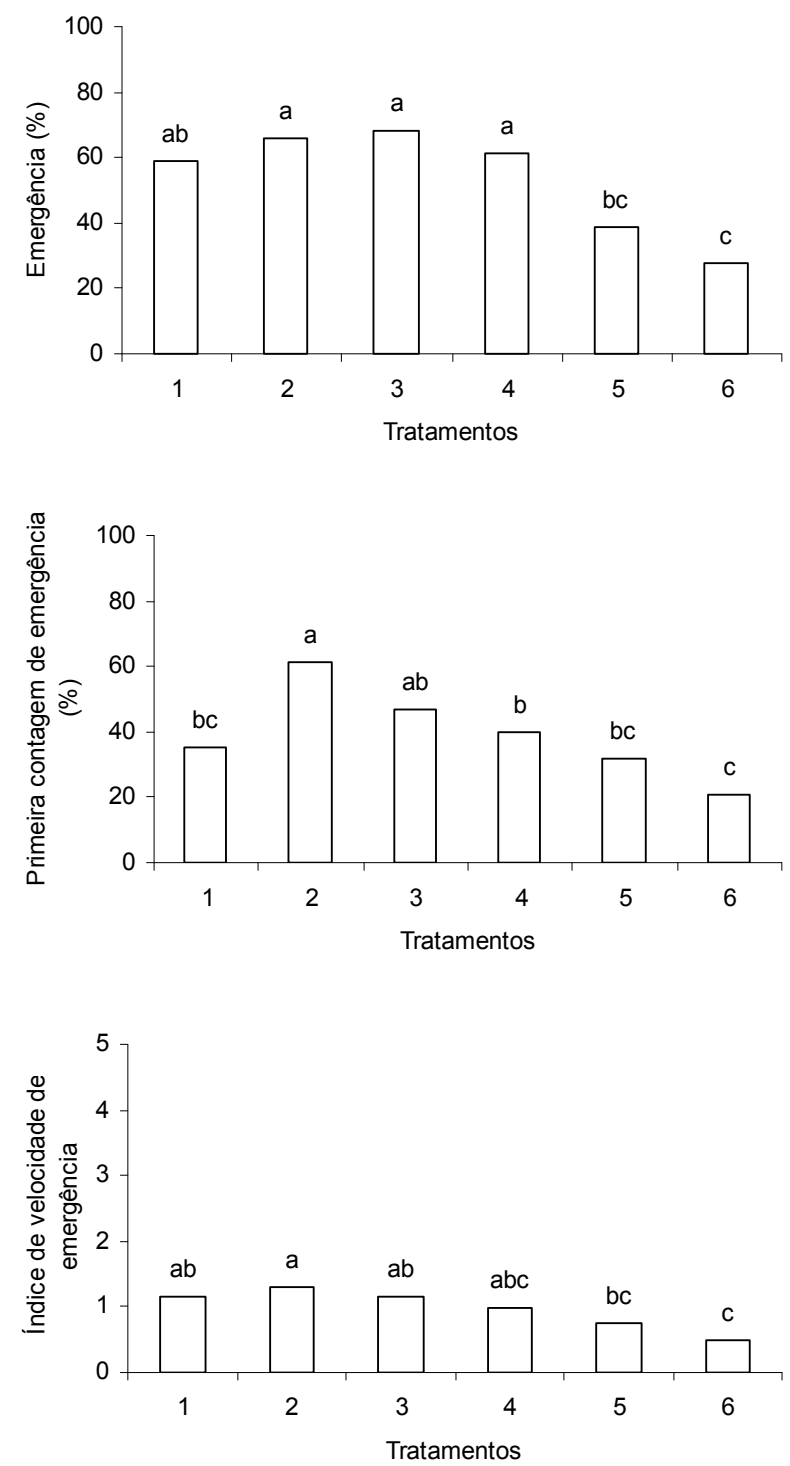

T1 - testemunha; T2 - escarificação mecânica com lixa d'água no 80 na região oposta a micrópila; T3, T4 e T5 - imersão das sementes em ácido sulfúrico concentrado por 15, 45 e 60 minutos, respectivamente e T6 - escarificação com lixa ${ }^{\circ} 80$, seguida de imersão em água fria por 24 horas.

*Médias seguidas de mesma letra não diferem estatisticamente entre si, pelo teste de Tukey, a 5\% de probabilidade.

Fonte: Elaboração dos autores. 
Figura 2. Comprimento de raiz primária (A), parte aérea de plântulas (B), massa seca do sistema radicular (C) e massa seca da parte aérea de plântulas de $S$. striata.

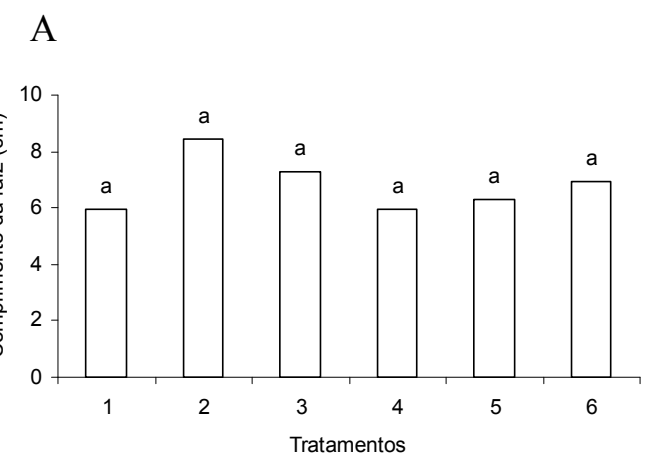

B

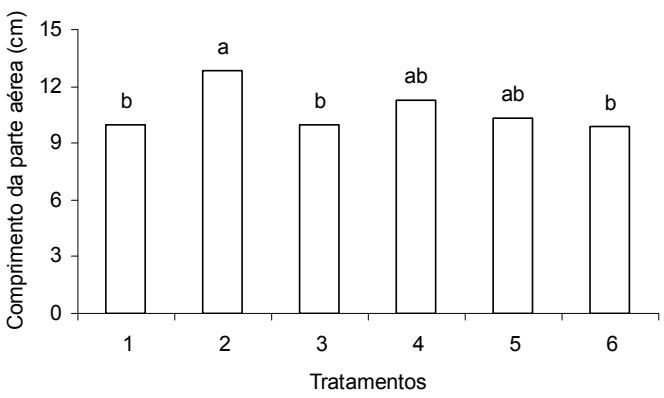

$\mathrm{C}$

$\mathrm{D}$
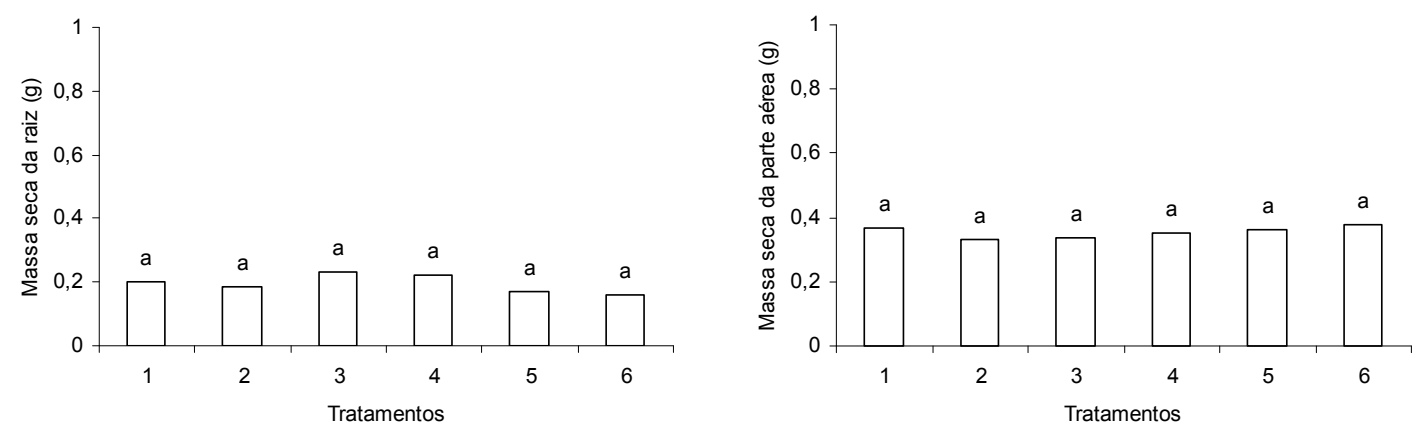

T1 - testemunha; T2 - escarificação mecânica com lixa d'água no 80 na região oposta a micrópila; T3, T4 e T5 - imersão das sementes em ácido sulfúrico concentrado por 15, 45 e 60 minutos, respectivamente e T6 - escarificação com lixa n ${ }^{\circ} 80$, seguida de imersão em água fria por 24 horas.

*Médias seguidas de mesma letra não diferem estatisticamente entre si, pelo teste de Tukey, a 5\% de probabilidade.

Fonte: Elaboração dos autores.

Sementes de Sterculia foetida submetidas à escarificação em um lado, seguida de embebição, originaram plântulas com maior massa seca da parte aérea, enquanto para a massa seca do sistema radicular não houve diferença significativa entre os tratamentos (SANTOS; MORAIS; MATOS, 2004), o mesmo não foi observado nesse estudo.

\section{Conclusões}

O tratamento de escarificação com lixa $n^{\circ} 80$ no lado oposto a micrópila favorece a porcentagem de plântulas na primeira contagem, sendo recomendado acelerar e uniformizar a emergência de sementes de Sterculia striata.

\section{Referências}

ALVES, A. U.; DORNELAS, C. S. M.; BRUNO, R. L. A.; ANDRADE, L. A.; ALVES, E. U. Superação da dormência em sementes de Bauhinia divaricata L. Acta Botânica Brasílica, São Paulo, v. 18, n. 4, p. 871-879, 2004.

ALVES, E. U.; BRUNO, R. L. A.; OLIVEIRA, A. P.; ALVES, A. U.; ALVES, A. U. Ácido sulfúrico na superação da dormência de unidades de dispersão de juazeiro (Zizyphus joazeiro Mart.). Revista Árvore, Viçosa, v. 30, n. 2, p. 187-195, 2006.

ALVES, M. C. S.; MEDEIROS FILHO, S.; ANDRADE NETO, M.; TEÓFILO, E. M. Superação de dormência em sementes de Bauhinia monandra britt. e Bauhinia ungulata L.-Cesalpinoideae. Revista Brasileira de Sementes, Brasília, v. 22, n. 2, p. 139-144, 2000. 
ARAÚJO, E. C. E. Chichá (Steculia striata St. Hil. et Naud.): uma nova opção para os mercados nacional e internacional de nozes. Informativo SBF, Brasília, v. 16, n. 4, p. 13-14, 1997.

BARBOSA, A. P.; SAMPAIO, P. T. B.; CAMPOS, M. A. A.; VARELA, V. P.; GONÇALVES, C. Q. B.; IIDA, S. Tecnologia alternativa para a quebra de dormência das sementes de pau-de-balsa (Ochroma lagopus Sw., Bombacaceae). Acta Amazônica, Manaus, v. 34, n. 1, p. 107-110, 2004.

BERTALOT, M. J. A.; NAKAGAWA, J. Superação da dormência em sementes de Leucaena diversifolia (Schlecht.) Bentham K156. Revista Brasileira de Sementes, Brasília, v. 20, n. 1, p. 39-42, 1998.

BEWLEY, J. D.; BLACK, M. Seeds: physiology of development and germination. New York: Plenum Press, 1994. $445 \mathrm{p}$.

BIANCHETTI, A.; TEIXEIRA, C. A. D.; MARTINS, E. P. Escarificação ácida para superar a dormência de sementes de pinho-cuiabano (Parkia multijuga Benth.). Revista Brasileira de Sementes, Brasília, v. 20, n. 1, p. 215-218, 1998.

BILIA, D. A. C.; BARBEDO, C. J.; MALUF, A. M. Germinação de diásporos de canela (Ocotea corymbosa (Meissn.) Mez - Lauraceae) em função da temperatura, do substrato e da dormência. Revista Brasileira de Sementes, Brasília, v. 20, n. 1, p. 189-194, 1998.

BORGES, E. E. L.; BORGES, R. C. G.; CANDIDO, J. F.; GOMES, J. M. Comparação de métodos de quebra de dormência em sementes de copaíba. Revista Brasileira de Sementes, Brasília, v. 4, n. 1, p. 9-12, 1982.

BRASIL, Ministério da Agricultura, Pecuária e Abastecimento. Regras para análise de sementes. Secretaria de Defesa Agropecuária. Brasília: MAPA/ ACS, 2009. 399 p.

CARVALHO, N. M.; NAKAGAWA, J. Sementes: ciência, tecnologia e produção. Jaboticabal: FUNEP, 2000. $588 \mathrm{p}$.

CRUZ, E. D.; CARVALHO, J. E. U. Methods of overcoming dormancy in Schizolobium amazonicum Huber ex Ducke (Leguminosae - Caesalpinioideae) seeds. Revista Brasileira de Sementes, Brasília, v. 28, n. 3, p. 108-115, 2006.

DEMINICIS, B. B.; ALMEIDA, J. C. C.; BLUME, M. C.; ARAÚJO, S. A. C.; PÁDUA, F. T.; ZANINE, A. M.; JACCOUD, C. F. Superação da dormência de sementes de oito leguminosas forrageiras tropicais. Archivos de Zootecnia, Córdoba, v. 55, n. 212, p. 401-404, 2006.
DUTRA, A. S.; MEDEIROS FILHO, S.; TEÓFILO, E. M.; DINIZ, F. O. Germinação de sementes de Senna siamea (Lam.) H.S. Irwin e Barneby - Caesalpinoideae. Revista Brasileira de Sementes, Brasília, v. 29, n. 1, p. 160-164, 2007.

EIRA, M. T. S.; CALDAS, L. S. Seed dormancy and germination as concurrent processes. Revista Brasileira de Fisiologia Vegetal, Campinas, v. 12, p. 85-104, 2000. Edição especial.

ELLIS, R. H.; HONG, T. D.; ROBERTS, E. H. Handbook of seed germination for genebanks. Rome: IBPGR, 1985. v. 2, p. 211-667.

ESCHIAPATI-FERREIRA, M. S.; PEREZ, S. C. J. G. A. Tratamentos para superar a dormência de sementes de Senna macranthera (Collad.) Irwin et Barn. (FabaceaeCaesalpinoideae). Revista Brasileira de Sementes, Brasília, v. 19, n. 2, p. 230-236, 1997.

FRANKE， L. B.; BASEGGIO, L. Superação da dormência em sementes de Desmodium incanum DC e Lathyrus nervosus Lam. Revista Brasileira de Sementes, Brasília, v. 20, n. 2, p. 420-424, 1998.

GARCIA, J.; DUARTE, J. B.; FRASSETO, E. G. Superação de dormência em sementes de sansãodo-campo (Mimosa caesalpiniaefolia L.). Pesquisa Agropecuária Tropical, Goiânia, v. 32, n. 1, p. 29-31, 2002.

HARTMANN, H. T.; KESTER, D. E.; DAVIES JUNIOR, F. T.; GENEVE, R. L. Plant propagation: principles and practices. 6. ed. New Jersey: Prentice-Hall, 1997. 770 p.

HERMANSEN, L. A.; DURYEA, M. L.; WEST, S. H.; WHITE, T. L.; MALAVASI, M. M. Pretreatments to overcome seed coat dormancy in Dimorphandra mollis Benth. Seed Science and Technology, Zürich, v. 28, n. 3, p. 581-595, 2000.

JELLER, H.; PEREZ, S. C. J. G. A. Estudo da superação da dormência e da temperatura em sementes de Cassia excelsa Schrad. Revista Brasileira de Sementes, Brasília, v. 21, p. 32-40, 1999.

KRAMER, P. J.; KOZLOWISK, T. T. Fisiologia das árvores. Lisboa: Fundação Calouste Gubbenkian, 1972. $745 \mathrm{p}$.

LOPES, J. C.; DIAS, P. C.; MACEDO, C. M. P. Tratamentos para acelerar a germinação e reduzir a deterioração das sementes de Ormosia nitida Vog. Revista Árvore, Viçosa, v. 30, n. 2, p. 171-177, 2006.

Tratamentos para superar a dormência de sementes de Ormosia arborea (Vell.) Harms. Brasil Florestal, Brasília, n. 80, p. 25-35, 2004. 
LORENZI, H. Árvores brasileiras: manual de identificação e cultivo de plantas arbóreas nativas do Brasil. 4. ed. Nova Odessa: Instituto Plantarum, 2002. $368 \mathrm{p}$.

MAGUIRE, J. D. Speed of germination-aid and in selection and evaluation for emergence and vigor. Crop Science, v. 2, n. 1, p. 176-177, 1962.

McDONALD, M. B.; COPELAND, L. O. Seed production: principles and practices. New Jersey: Chapmam \& Hall, 1997. 749 p.

MEDEIROS FILHO, S.; FRANÇA, E. A.; INNECCO, R. Germinação de sementes de Operculina macrocarpa (L.) Farwel e Operculina alata (Ham.) Urban. Revista Brasileira de Sementes, Brasília, v. 24, n. 2, p. 102-107, 2002.

MOUSSA, H.; MARGOLIS, H. A.; DUBE, P. A.; ODONGO, J. Factors affecting the germination of doum palm (Hyphaene thebaica Mart.) seeds from the semiarid of Niger, West Africa. Forest Ecology and Management, v. 104, n. 1, p. 27-34, 1998.

NAKAGAWA, J. Testes de vigor baseados no desempenho de plântulas. In: KRZYZANOWSKI, F. C.; VIEIRA, R. D.; FRANÇA NETO, J. B. (Ed.). Vigor de sementes: conceitos e testes. Londrina: ABRATES, 1999. cap. 2, p. 1-21.
POPINIGIS, F. Fisiologia da semente. Brasília: Agiplan, 1985.

ROVERSI, T.; MATTEI, V. L.; SILVEIRA JÚNIOR, P.; FALCK, G. L. Superação da dormência em sementes de acácia negra (Acacia mearnsii Willd.). Revista Brasileira de Agrociência, Pelotas, v. 8, n. 2, p. 161-163, 2002.

SAMPAIO, L. S. V.; PEIXOTO, C. P.; PEIXOTO, M. F. S. P.; COSTA, J. A.; GARRIDO, M. S.; MENDES, L. N. Ácido sulfúrico na superação da dormência de sementes de sucupira-preta (Bowdichia virgilioides H.B.K. Fabaceae). Revista Brasileira de Sementes, Brasília, v. 23, n. 1, p. 184-190, 2001.

SANTARÉM, E. R.; AQUILA, M. E. A. Influência de métodos de superação de dormência e do armazenamento na germinação de sementes de Senna macranthera (Colladon) Irwin \& Barneby (Leguminosae). Revista Brasileira de Sementes, Brasília, v. 17, n. 2, p. 205-209, 1995.

SANTOS, T. O.; MORAIS, T. G. O.; MATOS, V. P. Escarificação mecânica em sementes de chichá (Sterculia foetida L.). Revista Árvore, Viçosa, v. 28, n. 1, p. 1-6, 2004.

SMIDERLE, O. J.; SOUSA, R. C. P. Dormência em sementes de paricarana (Bowdichia virgilioides Kunth - Fabaceae - Papilionidae). Revista Brasileira de Sementes, Brasília, v. 25, n. 2, p. 48-52, 2003. 
